DOI: 10.21892/978-958-5547-66-7.1

\title{
1. La Constitución Política de 1991 el Estado Social de Derecho y la Salud: una relación compleja
}

Daniel Alzate Mora $^{1}$
Iván Vargas-Chaves

\section{Introducción}

Tras el fin de la guerra fría, en la década de los noventa, se generó un impulso global de (re)escribir textos constitucionales que dejaron atrás el pasado colonial, las extremas inequidades, los gobiernos autoritarios y la exclusión política, que se manifestó con fuerza en el sur global, en donde se destacan los casos de la India y Sudáfrica (Comaroff \& Comaroff, 2006; Rodríguez-Garavito, 2011).

Este impulso renovador de las formas constitucionales ha sido caracterizado como la emergencia de un tipo de «constitucionalismo aspiracional», el cual se propone "alcanzar el progreso social y un futuro mejor para la sociedad" (García Villegas, 2013). Sin embargo, el desarrollo de estos textos constitucionales han dejado en evidencia el desconocimiento tanto de la letra de la ley, como de su espíritu, y a pesar de ello se mantiene una fe en que las constituciones van a traer cambios sociales, como una forma de fetichismo jurídico ${ }^{3}$ (Comaroff $\&$ Comaroff, 2006).

1 Abogado de la Universidad de los Andes. Máster en Derecho Comparado de las Universidades de Milán, Messina y Córdoba, Italia y España. Doctor en Derecho de la Universidad del Rosario.

2 Abogado de la Universidad del Rosario. Máster en Derecho de la Universidad de Génova, Italia. Máster en Derecho Privado y Doctor en Derecho de la Universidad de Barcelona, España. Dottore di Ricerca (Dott. Ric.) de la Universidad de Palermo, Italia. Docente investigador de la Corporación Unversitaria del Caribe - CECAR.

3 El trabajo de Julieta Lemaitre Ripoll se enmarca en este contexto de un fetichismo jurídicos «aspiracional», en especial del texto de la Constitución de 1991. En su texto la autora analiza a fondo el proceso constitucional colombiano, y el uso de que han hecho del mismo por parte de movimientos sociales, concluyendo que a pesar de la violencia, la explotación y el despojo, se debe seguir apostando por la sociedad que se plasmó en el texto de la Constitución de 1991, que brinda las herramientas necesarias para el cambio 
La Constitución Política de 1991 el Estado Social de Derecho y la Salud: una relación compleja

En Latinoamérica este impulso de procesos constitucionales se produce tras el fin de las dictaduras y los gobiernos autoritarios de las décadas de los setenta y ochenta, en medio de la transición hacia la cultura garantista de los procesos democráticos y el respeto a los derechos humanos (Jiménez, 2008).

Este movimiento constitucional se inició en Brasil (1988) seguido por Colombia (1991), Paraguay (1992), Perú (1993), Bolivia (1994), Ecuador (1998) (Jiménez, 2008). Para el caso de Costa Rica (1989); México (1992) y Argentina (1994) se introdujeron reformas de amplio calado, semejantes a los demás cambios constitucionales (Uprimny, 2011).

Un caso interesante es la constitución de Venezuela (1999), considerada como puente entre las reformas de los años ochenta y noventa; modelo del socialismo del siglo XXI (Pisarello, 2010). Recientemente, el caso de Bolivia (2008) y el de Ecuador (2009), caracterizados como anticapitalistas y anticolonialistas, se presentaron planteando la superando del modelo liberal, para avanzar hacia otras formas experimentales como las plurinacionales, interculturales, aunque comparten algunos elementos del modelo aspiracional (Uprimny, 2011).

Estaemergencia de lacategoríaanalíticadel «nuevoconstitucionalismo» se ha centrado en analizar la convergencia (Merryman, 1981) de las formas jurídicas y las configuraciones de «aparato estatal». Sin embargo, sus análisis han dejado de lado los procesos sociales y políticos, e incluso los momentos históricos que han precedido cada cambio constitucional, respondiendo a una serie de dinámicas propias de cada proceso, pero también al momento neoliberal del capitalismo. Es a partir de esta operación que procesos tan distantes y contrapuestos, como por ejemplo el caso de Venezuela y Colombia, sean cobijados bajo el análisis del «neoconstitucionalismo» (Rodríguez-Garavito, 2012).

En este sentido, nos ocupamos de analizar con mayor detalle el proceso constitucional colombiano en su conformación y su desarrollo sobre la salud. Explicamos distintos tratamientos al interior de la Asamblea Nacional Constituyente (ANC), y de allí, concluimos que la Constitución Política de 1991 de Colombia hace parte de la estrategia del «consenso posneoliberal» (Stolowicz, 2012), para la reestructuración del capitalismo;

social (Lemaitre, 2009). 
manifestando con fuerza en materia de derechos sociales como la salud, y la fórmula de Estado Social de Derecho.

Para ello, el artículo parte por ubicar el contexto social y político en el que se enmarca el cambio constitucional de 1991 en Colombia, asimismo, sus antecedentes jurídicos-políticos, a fin de dar cuenta de las diversas estrategias utilizadas para su aprobación y desarrollo. Seguidamente, nos ocupamos de las discusiones que al interior de la ANC se dan sobre la salud, y la forma bajo la cual se configuran las políticas sociales bajo la nueva forma de Estado Social de Derecho, para presentar finalmente algunos elementos de discusión.

\section{El consenso político y social hacia la convocatoria de una Asamblea Nacional Constituyente}

Desde finales de la década de los años setenta se venía ventilando la idea de un cambio constitucional en Colombia, a partir de diversos actores y con intereses no siempre convergentes. En 1984 los grupos guerrilleros y movimientos sociales proponían convocar una Asamblea Nacional Constituyente con el fin de llegar a un espacio amplio de discusión y concertación, que no pasara por el Congreso de la República. En 1987 el tema fue retomado por el presidente Carlos Lleras Restrepo ante la escalada de la violencia contra la justicia en el país (Dávila, 2002).

A inicios de los noventa se empiezan a decantar estas iniciativas del cambio constitucional que rompiera con la tradición republicana de reformas al texto constitucional por uno de los partidos políticos tradicionales, liberal o conservador, o por una coalición tras una guerra civil, golpe de Estado, cambios anticipados o dirigidos por la élite gobernante (Valencia, 2010).

Se fue generando un consenso amplio en la sociedad en donde convergían los partidos tradicionales, los movimientos sociales, políticos y populares, nuevos partidos políticos, grupos armados desmovilizados, la academia, los estudiantes, e igualmente, los medios de educación en torno a la idea de convocar al pueblo para proclamar una nueva constitución (González, 1989). 
Los antecedentes jurídico-políticos del proceso constituyente: los intentos fallidos de una reforma constitucional en el gobierno Barco

La historia constitucional de Colombia ha estado caracterizada por un profuso cambio y reformismo constitucional desde su consolidación como Estado-nación. Según (Valencia 2010):

Colombia tuvo quince constituciones generales o nacionales: dos (en 1811) durante la guerra de independencia (18101819); cinco (en 1819, 1821, 1828 y 1830) durante la Gran Colombia (1819-1830); cuatro (en 1831, 1832, 1843 y 1853) durante la Nueva Granada (1830-1858); tres (en 1858, 1861 y 1863) durante la federación (1858-1886); y una, [...] la de 1886, en el umbral de la Regeneración (1886-1903).

Esta última Constitución de 1886 fue reformada en 67 oportunidades durante periodo comprendido entre 1894 y 1986. Pero tras este profuso cambio constitucional y el reformismo exacerbado no está el "genio jurídico" celebrado por los manuales de derecho constitucional, sino un "dispositivo ideológico enderezado a prevenir el cambio social y producir un consenso político" (Valencia, 2010).

Para el autor, la historia constitucional de Colombia se caracteriza como una sucesión de constituciones que describen como «cartas de batalla», en donde la facción triunfante se imponía por la fuerza de la ley. La guerra y violencia se libraba también en el campo jurídico y se evidencia la simultaneidad de ambos procesos.

Las cartas de batalla se erigen a modo de especie de culto a las formas republicanas, en tanto que las élites liberales y conservadoras lograban bloquear cualquier intento de la insurgencia por una transformación estructural. La hegemonía dominante ha construido un imaginario sobre el derecho como un medio para la organización de la sociedad capitalista, como proyecto ilustrado y, por lo tanto, racional, formal e impersonal, es decir, imparcial (Jiménez, 2008).

En el gobierno Barco se intentó en tres oportunidades una reforma adicional, la número 68 a la Carta de 1886, sin éxito. La primera reforma fue la convocatoria de un plebiscito, bloqueado por el bipartidismo para la construcción de un acuerdo con las fuerzas políticas tradicionales. Fruto de este acuerdo se propuso un referendo para adelantar la reforma, pero 
fue declarado inconstitucional por el Consejo de Estado, porque era el Congreso el único facultado para reformar la Constitución.

El gobierno optó por presentar un proyecto de acto legislativo, compuesto por 181 artículos, denominado «Democracia participativa y justicia social» que buscaba una legitimación de las instituciones, así como cumplir con los cambios políticos, sociales y económicos asumidos por el gobierno Barco. Se trataba de una transformación del Estado a la reestructuración del capitalismo, sustentada en la democracia participativa y la búsqueda de la paz (Jiménez, 2008).

Estas propuestas de reformas fallidas fueron asesoradas por Fernando Cepeda y César Gaviria. Cepeda, politólogo de la Universidad Nacional que "se alejó de la enseñanza pública para meterse de lleno en la vida privada" (Semana, 1986), participó en la creación de la facultad de derecho de la Universidad de los Andes y otros centros de investigación de dicha universidad, así como la docencia en la cátedra de ciencia política. En el gobierno Barco se desempeñó como ministro de Gobierno y de Comunicaciones, ligado a laélite intelectual norteamericana (Semana, 1986). César Gaviria también participó en los intentos de reforma, economista de la Universidad de los Andes, político profesional que ocupó los cargos de ministro de Hacienda y Crédito Público y ministro de Gobierno en la administración Barco (Estrada, 2005).

Ante este escenario, el gobierno de Barco y sus asesores se dieron a la búsqueda de un mecanismo que permitiera la reforma constitucional por vías diferentes a las dispuestas en la Carta Constitucional de 1886. En este contexto, la iniciativa de los estudiantes de las universidades privadas, «Todavía podemos salvar a Colombia», se alineaba a los objetivos del gobierno de un cambio constitucional. A pesar de sus diferencias ideológicas, «el movimiento estudiantil por la constituyente» también apoyó el proceso de la séptima papeleta (Lemaitre, 2009). Según Humberto de la Calle: "El movimiento estudiantil sirvió como detonante para mostrar que la forma de lograrlo era una especie de auto-convocatoria" (Jiménez, 2008). Con la particularidad de haber sido un movimiento estudiantil que no fue reprimido (Amaya, 2013) ni sufrió el terrorismo de Estado que por la misma época operaba en el exterminio de la Unión Patriótica (Calvo, 2008). El movimiento estudiantil se desintegró en 1990, antes de las elecciones de los constituyentes (Lemaitre, 2009). 
El estudio jurídico para buscar la viabilidad del cambio constitucional, ante las vicisitudes de los intentos en el gobierno Barco y que, además, no tuviera que pasar por el control de la Corte Suprema de Justicia (Ahumada, 1996) fue elaborado por el ministro de Comunicaciones, Fernando Cepeda, el ministro de Gobierno, César Gaviria, con el apoyo de Manuel José Cepeda, hijo del ministro Fernando Cepeda, y uno de los miembros más jóvenes del kínder del presidente Gaviria (Estrada, 2005). Manuel José Cepeda es abogado de la Universidad de los Andes con estudios de posgrado en la Universidad de Harvard, y tiene un papel protagónico en la estrategia jurídica, una «astucia abogadil» (Valencia, 2010) que permitiría la convocatoria a la Asamblea Nacional Constituyente.

De hecho, Cepeda, quien tenía una estrecha amistad con Fernando Carillo, profesor de la Universidad Javeriana y la Universidad del Rosario, participó activamente en el movimiento estudiantil, el cual abandonó para formar parte de la Asamblea Nacional Constituyente (Lemaitre, 2009), jugaron un papel importante de articulación entre la propuesta de los estudiantes y el gobierno para la convocatoria a la Asamblea Nacional Constituyente. El carácter pragmático del escrito para el cambio constitucional fue denominado «Plan de asalto» (Ahumada, 1996).

La «teoría constitucional» que permitió abrir el camino a la convocatoria de la Asamblea Constitucional se dio a través del decreto de estado de sitio 927 de 1990, durante el gobierno de Barco. Según Cepeda, "un pueblo que se auto-convoca y un estado de sitio que se puede utilizar para crear las bases políticas e institucionales para la paz: en esas dos frases se resume la teoría constitucional construida para abrirle un camino a la asamblea dentro del orden jurídico" (Cepeda 1993).

Esta declaración del estado de sitio abrió las puertas para que el próximo presidente, César Gaviria (1990-1994) liderara el proceso constituyente. Sin embargo, el procurador general de la nación, Alfonso Gómez Méndez alertó a la Corte Suprema de Justicia del camino jurídico que adoptaba el gobierno para avanzar en la reforma constitucional. En su criterio, Ahumada (1996), expresa:

Lo que se quiere presentar como la suprema manifestación de la democracia participativa puede quedar reducido a un cheque en blanco para que el próximo presidente, y sus asesores, veinte, 
treinta o cuarenta individuos, sean quienes decidan cuál es el camino a seguir para convocar la «Constituyente»

\section{La convocatoria de la Asamblea Nacional Constituyente}

Dando continuidad a los avances de la administración Barco para una reforma constitucional, el gobierno de Gaviria se aseguró de lograr un acuerdo político con las fuerzas políticas tradicionales y el nuevo partido político Alianza Democrática M-19 (AD-M19), con el fin de llevar a buen término la reforma. De este acuerdo político fue excluida la Unión Patriótica y los estudiantes - a pesar de ser estos últimos los convocantes- (Dávila, 2002).

A través del decreto 1926 de 1990 se presentó a la opinión pública el acuerdo político sobre la Asamblea Nacional Constitucional, en donde se determinaron los elementos procedimentales de la Asamblea así como su alcance y temario a discutir (Jiménez, 2008). En una decisión controvertida, aprobada con 14 votos de 26 posibles (Ahumada, 1996; Cepeda, 2007a), La Corte Suprema de Justicia se pronunció sobre la constitucionalidad del decreto. Sin embargo, consideró que la limitación temática era contraria a la convocatoria del constituyente primario, que no podía ser limitado en su soberanía. Con el fallo de la Corte, la que era una «Asamblea Nacional Constitucional» adquirió el carácter de «Constituyente», por lo que tenía plena libertad para avanzar en una reforma estructural del Estado y sus instituciones, y establecer un nuevo «pacto social» sin ninguna limitación. Esto presentaba un obstáculo para el proyecto del gobierno Gaviria, no obstante, como explicaremos el gobierno logró mantener su decálogo temático y metodológico como eje central sobre el cual va a ser desarrollado el proceso de la ANC (Jiménez, 2008).

El 9 de diciembre de 1990 se votó la conformación de la Asamblea Nacional Constituyente. Con un total de 70 delegados, se conformó un foro de amplia pluralidad de actores: desde los partidos tradicionales, liberal con 25 constituyentes; 9 para conservador y 11 al Movimiento de Salvación Nacional formado por una división del partido conservador y liderado por Álvaro Gómez Hurtado. Por Alianza Democrática M-19 se contó con 19 constituyentes y los indígenas; la Unión Patriótica y los grupos evangélicos tuvieron cada uno dos delegados. El partido revolucionario de 
los trabajadores (PRT) y el movimiento indígena Quintín Lame, tuvieron un representante cada uno, pero sin derecho a voto (Jiménez, 2008).

No obstante, la conformación de la Asamblea Nacional Constituyente «nace muerta» (Mejía, 2002a, 2002b), pues el mismo día en que se produce la elección de los constituyentes, el gobierno lanza una ofensiva militar contra el principal campamento del secretariado de las Fuerzas Armadas Revolucionarias de Colombia-Ejército del Pueblo (FARC-EP), ubicado en Casa Verde —este representaba el símbolo de los diálogos de paz durante diez años con esa guerrilla-. Los asesores del gobierno Gaviria, aplicando sus conocimientos técnicos adquiridos en Estados Unidos en los manuales de ciencia política, concluyeron que el ataque conduciría a un éxito político y militar, toda vez que las FARC-EP habían quedado sin ningún apoyo tras la caída del muro de Berlín y el ocaso de la Unión Soviética (Medina, Toloza, Beltrán, Romero, \& Caicedo, 2009). El ataque no dejó ningún éxito militar y significó un fracaso político para el gobierno (Calvo, 2008).

Este ataque a la guerrilla tenía un poder simbólico importante, ya que la Asamblea Nacional Constituyente se convocó para construir un pacto de paz. Esta acción militar cerraba las posibilidades de diálogo con los grupos alzados en armas que no integraran el proceso de cambio constitucional (Mejía, 2002b). En ese sentido, la Constitución de 1991 no lograba romper del todo con la tradición constitucional de Colombia de «cartas de batalla» (Valencia, 2010).

Sin embargo, el proceso de la ANC produjo un cambio en la tradición constitucionalista del país que dio paso a una discusión sobre el sistema político y el fin del bipartidismo del Frente Nacional, los derechos fundamentales, la democracia, la forma de Estado entre otros aspectos introducidos por el pacto constitucional. "La Constitución de 1991 se nos ha presentado, no sin justas razones, como una Constitución progresista, antiformalista, el origen del nuevo derecho, de textura abierta, garantista, vanguardista, tanto por los derechos fundamentales que consagró, por la figura del Estado social de derecho que los respalda y por el esquema de democracia participativa que propiciaba" (Mejía, 2002a, 2002b). 


\section{La Constitución Política de 1991}

La constitución tiene un papel central en la reconfiguración del capitalismo en Colombia, pues va a encubrir la dominación y explotación, en tanto que su introducción viene legitimada a través de la retórica de la democracia participativa y la búsqueda de la paz. Siguiendo los análisis críticos al cambio constitucional (Alzate, Oviedo, Velosa, \& Abadia, 2013; Estrada, 2004, 2005; Jiménez, 2008; Mejía, 2002a, 2002b; Moncayo, 1990, 2002, 2004), dicha modificación dio legitimidad a la avanzada neoliberal tras las figuras progresistas de la ampliación de la democracia participativa, la definición del Estado como Social de Derecho y los derechos humanos.

Los elementos estructurales para la reestructuración del capitalismo quedaron intactos, y a través de la «ambigüedad calculada» (Calvo, 1994), la ductilidad de las formas constitucionales (Zagrebelsky, 1999) y la flexibilidad de enunciados del texto constitucional como: «economía de mercado»; «libertad de empresa»; «eficiencia», se ha permitido una interpretación y aplicación del texto constitucionales según los mandatos de la reestructuración capitalista.

Existe un consenso por parte de la dogmática del derecho constitucional de valorar la Constitución de 1991 en general como parte del nuevo constitucionalismo o «constitucionalismo aspiracional». Las renovadas formas constitucionales en América Latina se ubican en el tránsito a la democracia, que fue celebrado como una transformación radical de dichas sociedades. En especial la cláusula del Estado Social de Derecho se ha interpretado como un principio que irradia todo el texto constitucional en tanto que orienta la actividad del Estado en todos sus aspectos y que implica a su vez un compromiso fuerte con la justicia social y la libertad (Arango, 2004; Cepeda, 2007b; Lemaitre, 2009; RodríguezGaravito, 2011; Uprimny, 2001, 2011).

Contrario a este consenso, proponemos argumentar que el Estado Social de Derecho no puede analizarse de forma aislada al momento histórico en que se produce el cambio constitucional en Colombia y la reestructuración del capitalismo bajo la égida neoliberal. En este sentido, el Estado Social de Derecho lo identificamos, siguiendo a Stolowicz (Stolowicz 2012), como el elemento articulador que está operando en la era de los regímenes democráticos para América Latina. Con respecto al 
caso específico de Colombia es la fórmula del Estado Social de Derecho la que condensa y sintetiza la reestructuración capitalista y su forma de legitimación, vaciando del contenido de justicia social que evoca la fórmula del Estado Social de Derecho.

\section{El Estado Social de Derecho: el elemento articulador del neoliberalismo en Colombia}

En cada país de América Latina la reestructuración capitalista del neoliberalismo se impone desde diversos ámbitos, en Colombia se denominó Estado Social de Derecho, y la reestructuración se centró en los mecanismos jurídico-políticos. A partir de los análisis de Beatriz Stolowicz (Stolowicz, 2012), en una perspectiva de larga duración, el Estado Social de Derecho no es antagónico ni está en contradicción con el modelo económico impuesto en Colombia de forma simultánea a su consagración, en la Constitución Política de 1991. Por el contrario, asumimos con la autora que el Estado Social de Derecho ha sido el elemento que permitió que a inicios de la década del noventa se legitimara la estrategia para la realización del ideal posneoliberal de «democracia de propietarios» y la política social de economía neoclásica.

Según Salomón Kalmanovitz, quien se arrepiente de no haber participado en la Asamblea Nacional Constituyente (El Espectador, 2010), el diseño de la Constitución de 1991 no es de corte neoliberal, pues no se desprendió de una concepción del Estado paternalista y caritativa, que fue el modelo de la Constitución de 1886. No obstante, el nuevo pacto político buscó fortalecer la esfera política y económica de la sociedad a través de un balance entre Estado-mercado-individuo. Para Kalmanovitz (2001):

El concepto de ciudadanos que surge de la soberanía popular es que tienen libertad política y económica. Tienen derechos y responsabilidades y pueden desplegar iniciativas para hacer negocios y para construir Estado. Pueden transar entre ellos como individuos iguales, y lo que voluntariamente decidan debe ser garantizado por la ley. Los individuos libres toman sus decisiones y deben asumir responsabilidades de sus actos. Todo lo que se especifique en un contrato firmado por ellos debe cumplirlo. Deben pagar sus deudas, responder por sus 
obligaciones con su familiar y contribuir para construir un Estado fuerte y justo.

La dogmática constitucional ha establecido una interpretación del Estado Social de Derecho como forma de Estado, que evoca el Estado de Bienestar europeo, y en especial, el de la Constitución de Weimar (López, 2003), de un compromiso fuerte y decidido por la justicia social y la garantía asimismo protección de los derechos económicos, sociales y culturales reconocidos en la Constitución. Por otra parte, se ha establecido que las políticas económicas de la década de los noventa van en contravía de los postulados del Estado Social de Derecho, por no contemplar la «perspectiva de los derechos sociales» en su desarrollo y formulación, lo cual genera una contradicción entre los desarrollos de la política social con los postulados de la Constitución de 1991.

Esta contradicción se manifiesta de forma especial en el campo de la salud. Por una parte, la Constitución reconoce la salud como un derecho social, a cargo del Estado, y que representa una manifestación concreta de la forma Estado Social de Derecho debiendo ser garantizada según los principios de universalidad, solidaridad y eficiencia. Pero, por otra parte, el sistema de salud creado en la Ley 100 de 1993 no ha logrado garantizar los postulados de la Constitución, desarrollando una política pública que no alcanza a estar en plena sintonía con la Constitución (López, 2008a).

La Corte Constitucional en su desarrollo jurisprudencial ha desarrollado una amplia dogmática sobre el Estado Social de Derecho para la interpretación de los postulados de la Constitución. Sin embargo, sus argumentaciones coherentistas (Pérez, 2006) han logrado establecer que existe una política pública de salud, contenida en la Ley 100 de 1993, dirigida a la satisfacción del derecho constitucional a la salud, por lo tanto, no encuentra contradicción en ambos procesos.

Lo que aquí queremos argumentar es que la coherencia y el vínculo entre la Constitución y el sistema de salud no se deriva de un procedimiento interpretativo, por el contrario, hace parte de una estrategia cuyo propósito es legitimar la avanzada neoliberal y la creación de nuevos mercados, como el de la salud, para la acumulación capitalista. En este sentido, el Estado Social de Derecho y la política de salud de la Ley 100 de 1993 resultan coherentes como parte del mismo proyecto por la acumulación del capital, 
La Constitución Política de 1991 el Estado Social de Derecho y la Salud: una relación compleja

desde dispositivos muy finos, que ideológicamente están construidos con el objeto de dar la garantía de la vida, pero que sus desarrollos evidencian una política de muerte.

Al respecto, nos explica Pablo Dávalos: "un régimen que se arroga el derecho a la vida, también lo hace con el derecho a la muerte. La biopolítica tiene una contraparte con la tanatopolítica. La legitimación del derecho a la vida abre el espacio político e histórico para justificar y legitimar el derecho a la muerte" (Dávalos, 2011).

De esta forma entendemos que no existe contradicción entre el Estado Social de Derecho y las políticas sociales, sino que, por el contrario, son las formas novedosas en que se legitima la disposición de la vida y la muerte. La dialéctica entre la biopolítica y la tanatopolítica se refleja en el sistema de salud, y la tensión que produce conceptualizar la salud como un derecho, vinculado estrechamente con la vida o como un servicio público, asociado a la acumulación capitalista de los mercaderes de la salud, a su vez, relacionado con la muerte ante la falta de recursos para pagar los servicios necesarios. A continuación, exponemos de qué manera se planteó esta tensión al interior de la ANC.

\section{La salud entre derecho y servicio público en la Constituyente de 1991}

Una de las transformaciones más importantes de la Constitución Política de 1991 es la amplia carta de derechos constitucionales consagrados en el Título II, De los derechos, las garantías y los deberes. No obstante, en el texto de la Constitución y el proceso constituyente se dejó abierto el debate de la configuración de la salud ya sea como derecho o servicio público.

La salud recibió diversas categorizaciones en la ANC, en principio como derecho, y luego, de forma ambigua que oscilaba entre un servicio público al que se accede a través del mercado, pero al mismo tiempo, se le define de forma gaseosa como parte del derecho irrenunciable a la seguridad social.

La configuración de la salud en términos de derecho se debatió entre los constituyentes que afirmaban su naturaleza de derecho social, el cual está limitado a los desarrollos legislativos sobre su contenido y alcance; mientras que, por otra parte, otros constituyentes argumentan que la salud 
se definió a modo de servicio público, bajo la nueva noción de servicio volcada al mercado y asimismo a la acumulación de capital por parte de empresas privadas.

Para analizar la configuración de la salud, ya sea como derecho o servicio público, se toma como punto de partida el informe-ponencia remitido a la subcomisión segunda de la Asamblea Nacional Constituyente, titulado: Proyecto de nueva carta de derechos, deberes, garantías y libertades.

Explican los constituyentes en su informe que para la determinación de los derechos a incluir en la nueva Carta constitucional se tuvo en cuenta la evolución histórica del concepto de derechos fundamentales. En esta evolución se han diferenciado la concepción liberal clásica y los derechos económicos, sociales y culturales. No obstante, más allá de las discusiones ideológicas entre grupos de derechos, la ponencia concluye que ambos deben ser reconocidos en tanto se complementa y amplía el marco de protección constitucional que les permita contar con las condiciones materiales para el disfrute de los derechos individuales de la tradición liberal.

Otro aspecto importante del informe es la discusión que se planteó acerca del valor normativo de los derechos económicos, sociales y culturales, en el sentido de considerarlos como derechos justiciables y tener plena exigibilidad jurídica; o por el contrario, serían marcos de sentido de orientación en el desarrollo del Estado. Al respecto, el informe definió que estos derechos son considerados: "Como situaciones jurídicas constitutivas de verdaderos derechos", en tanto algunos ya están regulados por el Estado o las condiciones de desarrollo del país no pueden constituir un impedimento para el reconocimiento de esta clase de derechos; mientras se espera en un futuro que las condiciones sociales, económicas, políticas, al igual que las jurídicas, cambien y se dé plena realización a los derechos sociales.

El informe incluyó dentro de su propuesta de la nueva carta de derechos, el de la salud y la seguridad social en los siguientes mencionados a continuación.

Artículo $37^{\circ}$. De la salud y la seguridad social: La protección de la salud y la seguridad social son deberes del Estado y derechos de las personas, garantizados mediante politicas económicas y sociales que a través de un adecuado sistema de seguridad 
social, reduzca el riesgo de enfermedad y aseguren el acceso igualitario a los servicios de salud para su prevención, protección y recuperación.

Una ley marco determinará el desarrollo progresivo del régimen de la seguridad social integral, incluyendo la asistencia pública, el subsidio al desempleo y la licencia de maternidad. Estos derechos se extienden a los trabajadores de la cultura" (Const., 1991, art. 37).

Sin embargo, en este mismo articulado aparece la noción contrapuesta a la de derecho a la salud, la de servicio público. Al respecto, el artículo 44 dispuso:

Artículo $44^{\circ}$. De los servicios públicos básicos: El Estado tiene el deber de satisfacer las necesidades básicas de la comunidad, tales como servicios públicos, de salud, educación, vivienda, comunicaciones, agua potable, luz, recreación y deporte, mediante políticas económicas y sociales eficaces" (Const., 1991, art. 44).

La comisión codificadora de la ANC, para julio de 1991, definía, en el artículo 49, la salud como servicio público y derecho fundamental. No obstante, en la Gaceta Constitucional del 10 de octubre de 1991 la Plenaria reajustó los artículos 48 y 49 en donde la definición de la salud como derecho fundamental fue suprimida de la redacción final. En el artículo 49 se incorporó la mención sobre los principios de eficiencia, universalidad y solidaridad como orientadores y sustento para la prestación de los servicios de salud. El artículo 49 también fue modificado pues establecía que el servicio público de salud debía ser organizado, dirigido y reglamentado "por medio de entidades públicas"; éste último elemento de entidades públicas fue eliminado en la plenaria (Lamprea, 2011).

Según Lamprea estas modificaciones no le restaron valor a la salud como derecho. El autor llega a esta conclusión retomando las discusiones de plenaria y la intervención de Navarro Wolff, constituyente por la AD-M19, que propuso un artículo independiente para la salud. Por ello, explica que debe hacerse una lectura conjunta del primer inciso del artículo 49 que estableció: "la atención de la salud y el saneamiento ambiental son servicios públicos a cargo del Estado" con el primer inciso del artículo 48: 
"La Seguridad Social es un servicio público de carácter obligatorio que se prestará bajo la dirección, coordinación y control del Estado, en sujeción a los principios de eficiencia, universalidad y solidaridad, en los términos que establezca la Ley" (Const., 1991, art. 48).

Lo que el autor plantea es una interpretación "coherentista" (Pérez, 2006) de la discusión al interior de la ANC, y su resultado final en la Constitución, la cual puede ser una lectura posible sobre el espíritu constituyente, tendiente a ocultar la holgura hermenéutica (Calvo, 1994) de la imprecisión constitucional en la definición de la salud.

Pero cuando se complementa el análisis del tratamiento de la salud en la ANC, con la discusión de los asuntos económicos en la Constitución, emerge la ambigüedad calculada, ductilidad, amplitud y flexibilidad de las formas en que el capital privado se introduce en el texto para configurar la definición de la salud, así como los servicios públicos, que van a legitimarse desde el modelo de Estado Social de Derecho.

Las discusiones de los asuntos económicos, siguiendo a Jiménez (Jiménez, 2008), fueron muy reducidas, en parte a los pocos proyectos presentados para discusión al interior de las comisiones económicas de la ANC, pero también reflejan el férreo control que ejerció el gobierno sobre esta, con el fin de mantener su desarrollo en el marco del proyecto temático y procedimental que había fijado en su propuesta de reforma.

El desarrollo de las deliberaciones se dio en el marco de consensos por fuera de la $A N C^{1}$. Según Perry se propuso un principio orientador de las discusiones en asuntos económicos que permitió zanjar el debate entre

1 Sobe el particular señala Guillermo Perry, quien participó como Constituyente en la comisión $\mathrm{V}$ de asuntos económicos en donde explica que la discusión del Banco de la República se caracterizó porque: "[...] El Banco no se limitó a preparar la propuesta original, incorporada con pocas modificaciones en le proyecto de reforma constitucional que presentó el gobierno, sino que condujo en todo momento el más activo y efectivo lobby al interior de la Asamblea. Cómo no recordar los finos desayunos y almuerzos, servicios en los salones del Banco, a los que fuimos invitados, por turnos, todos los miembros de la Comisión Quinta para escuchar la explicación y justificación de esta importante propuesta; o el completo dosier que nos fue entregado, muy bien compuesto y editado por cierto; o la efectividad de los artículos, gráficos y cálculos con los que se convenció a mis colegas en la Asamblea de que al otorgar autonomía al Banco se derrotaría la inflación Perry, G. (1995). "La automonía del Banco de la República." Debates de coyuntura económica Septiembre(36). 
neoliberalismo, en un extremo, contra intervencionismo del Estado en la economía, al otro extremo. Desde una concepción moderna de la economía el grupo de constituyentes liberales presentó un texto a la Asamblea en donde se planteó como guía para las deliberaciones, la fórmula: "tanto mercado como sea posible y tanto Estado como sea necesario" (Perry, 2011).

Desde esta óptica la lectura sobre la salud, la seguridad social los servicios públicos y la fórmula de Estado Social de Derecho adquieren una connotación distinta, en tanto que su amplitud y flexibilidad da cabida a la incorporación de las lógicas del mercado: "tanto mercado como sea posible", en donde se instala el lucro-mercado privado, pero que está complementado con "tanto Estado como sea necesario", que radica en sus funciones de control, regulación, inspección y vigilancia al igual que políticas sociales de focalización.

Es preciso anotar cómo el artículo 48 que consagra el derecho irrenunciable a la seguridad social, al mismo tiempo dispone que:

El Estado, con la participación de los particulares, ampliará progresivamente la cobertura de la Seguridad Social que comprenderá la prestación de los servicios en la forma que determine la Ley. La Seguridad Social podrá ser prestada por entidades públicas o privadas, de conformidad con la ley". El artículo 49, sobre la salud en este mismo sentido establece: "Corresponde al Estado [...] establecer las políticas para la prestación de servicios de salud por entidades privadas, y ejercer su vigilancia y control. Así mismo, establecer las competencias de la Nación, las entidades territoriales y los particulares, y determinar los aportes a su cargo en los términos y condiciones señalados en la ley. (Const., 1991, art. 48-49)

Por su parte, el artículo 365 define los servicios públicos, su prestación y el papel del Estado en los siguientes términos:

Los servicios públicos son inherentes a la finalidad social del Estado. Es deber del Estado asegurar su prestación eficiente a todos los habitantes del territorio nacional. Los servicios públicos estarán sometidos al régimen jurídico que fije la ley, podrán ser prestados por el Estado, directa o indirectamente, por comunidades organizadas, o por particulares. En todo caso, 
el Estado mantendrá la regulación, el control y la vigilancia de dichos servicios. Si por razones de soberanía o de interés social, el Estado, mediante ley aprobada por la mayoría de los miembros de una y otra cámara, por iniciativa del Gobierno decide reservarse determinadas actividades estratégicas o servicios públicos, deberá indemnizar previa y plenamente a las personas que, en virtud de dicha ley, queden privadas del ejercicio de una actividad lícita.

Pero la estrategia neoliberal no se limitó al texto constitucional, sino que permeó todo el ordenamiento jurídico, en la configuración que Jairo Estrada caracteriza como "la construcción de un orden [de derecho positivo] neoliberal" (Estrada, 2004). El proyecto político neoliberal ha sido revestido por una dulcificación jurídica, al ajustarse a las "reglas del juego" democrático, en donde las iniciativas gubernamentales han surtido todos los trámites legales por el Congreso de la República y han contado con la bendición del poder judicial al encontrarse ajustadas a la Constitución.

La inserción de todos los individuos al mercado, ahora como propietarios, sin distingo de raza, etnia, religión, clase social, es una de las manifestaciones del derecho a la igualdad (Const., 1991, art. 13), en su carácter formal, fundamental al funcionamiento del mercado capitalista, en donde no se tienen en cuenta este tipo de distinciones. Sin embargo, también se consagra la igualdad material y efectiva, como manifestación del modelo de Estado Social de Derecho, en donde se tomarán medidas a favor de grupos históricamente discriminados o en situación de debilidad manifiesta, sin que ello implique el establecimiento del "igualitarismo". El Estado Social de Derecho se ha venido desarrollando desde el paradigma de las oportunidades para el goce de derechos a través del mercado. Esta forma de Estado aparece ya desde los proyectos de reforma a la Constitución. Sobre el particular el proyecto planteaba:

El Estado social, entendido como idea regulativa, significaría que para el Estado existiría una obligación de buscar la justicia social en sus actuaciones. Éste debería promover la igualdad de los diferentes grupos sociales, lo cual no significa la implantación del "igualitarismo" sino que todos los sectores de la población deberían tener igualdad de posibilidades para el pleno goce de sus derechos. 
En este planteamiento se sintetiza el enfoque desde el cual se abordan las políticas sociales, en especial el caso de salud que nos ocupa. En este sentido, la fórmula Estado Social de Derecho se despoja de todo condicionamiento histórico que marca las reivindicaciones sociales de la clase trabajadora. De esta manera, el Estado Social de Derecho se puede acomodar de tal forma que resulta funcional a la reestructuración capitalista, manteniendo intacto el modelo de lucro-mercado capitalista que la Constitución de 1991 legitima y justifica.

\section{Discusión}

El consenso sobre la Constitución Política de 1991 como un «pacto revolucionario» (Cepeda, 2007b), como fue catalogada por el presidente César Gaviria, ha sido la calificación que también ha recibido por los análisis jurídicos sobre la Constitución y la propia Corte Constitucional, que coinciden en el carácter progresista, antiformalista y de compromiso social (López, 2008b).

Sin embargo, un análisis detallado del proceso constitucional, el contexto histórico en que se desarrolló y el tratamiento dado en especial a la salud en su interior, develan que el carácter progresista y garantista de derechos estaba encaminado a la legitimación de un ajuste del modelo neoliberal.

El Estado Social de Derecho se limitó a que las políticas sociales y la prestación de los servicios públicos, ahora a cargo de los operadores privados en los nuevos mercados, se lleven bajo condiciones de equidad y solidaridad. En ese sentido, se legitima la división de clases al interior de la sociedad, en tanto que quienes tengan capacidad de pago tendrán que acudir al mercado para la satisfacción de sus derechos, y a quienes no tengan los recursos económicos, el Estado Social de Derecho les suplirá dichos servicios por la vía de subsidios,-

A través de esta forma los derechos sociales adquieren un carácter patrimonial (Giraldo, 2013; Giraldo, 2007), ya que es el patrimonio individual el que determina si el Estado debe o no garantizar la satisfacción de dichos derechos. De esta manera, el Estado Social de Derecho adquiere un carácter discursivo con una fuerte carga retórica, que no logra trascender 
las políticas de exclusión, discriminación, explotación y despojo, que han caracterizado al Estado colombiano, en especial el caso de la salud (Alzate et al., 2013).

\section{Referencias}

Ahumada, C. (1996). El modelo neoliberal y su impacto en la sociedad colombiana. Bogotá: El Áncora Editores.

Alzate, M. D., Oviedo, M. D. G., Velosa, L. P., \& Abadia, C. E. (2013). Derecho lucro-destructivo: vivencias de la ideología posneoliberal en salud. In C. E. Abadia, A. Góngora, M. A. Melo Moreno \& C. Platarrueda (Eds.), Salud, normalización y capitalismo en Colombia. Bogotá: Univesidad Nacional de Colombia. Facultad de Ciencias Humanas. Centro de Estudios Sociales (CES). Grupo de Antropología Médica Crítica. Ediciones Desde Abajo. Universidad del Rosario.

Amaya, R. (2013). Democratización sin represión, excepción en el caso colombiano: el movimiento estudiantil de la séptima papeleta o todavía podemos salvar a Colombia. Revista de Derecho Público, Enero-Junio(30).

Arango, R. (2004). Derechos, constitucionalismo y democracia (Vol. 33). Bogotá: Universidad Externado de Colombia.

Calvo, G. M. (1994). Los fundamentos del método jurídico: una revisión crítica. Madrid: Tecnos.

Calvo, O. H. (2008). Colombia, laboratorio de embrujos. Democracia y terrorismo de Estado. . Madrid: Foca ediciones.

Cepeda, E. M. J. (2007a). La Constitución y sus orígenes: de la política constitucional al derecho constitucional Polémicas Constitucionales. Bogotá: Legis.

Cepeda, E. M. J. (2007b). Polémicas constitucionales. Bogotá: Legis.

Comaroff, J. L., \& Comaroff, J. (2006). Law and Disorder in the Postcolony: An Introduction. In J. Comaroff \& J. L. Comaroff (Eds.), Law and Disorder in the Postcolony (pp. 1-56). Chicago and London: The University of Chicago Press.

Constitución Política de Colombia [Const.] (1991) Artículo 13. 2da Ed. Legis.

Constitución Política de Colombia [Const.] (1991) Artículo 37. 2da Ed. Legis. 
La Constitución Política de 1991 el Estado Social de Derecho y la Salud: una relación compleja

Constitución Política de Colombia [Const.] (1991) Artículo 44. 2da Ed. Legis.

Constitución Política de Colombia [Const.] (1991) Artículo 48. 2da Ed. Legis.

Constitución Política de Colombia [Const.] (1991) Artículo 49. 2da Ed. Legis.

Dávalos, P. (2011). La democracia disciplinaria. El proyecto posneoliberal para América Latina. Bogotá: Educiones desde Abajo.

Dávila, L. d. G. A. (2002). Democracia pactada. El frente nacional y el proceso constituyente del 91. Bogotá: Uniandes.

Elespectador.com. (2010). "Soy una madre": Salomón Kalmanovitz. El Espectador.

Estrada, Á. J. (2004). Construcción del modelo neoliberal en Colombia. 1970-2004. Bogotá: Ediciones Aurora.

Estrada, Á. J. (2005). Elementos preliminares para una caracterización de la elite intelectual de las reformas estructurales en Colombia. Ensayos críticos, septiembre (1).

García Villegas, M. (2013). Constitucionalismo aspiracional. Araucaria, 15(129), 77-97.

Giraldo, C. (2013). Política social contemporánea. In C. Giraldo (Ed.), Política social contemporánea en América Latina. Entre el asistencialismo y el mercado. Bogotá D.C.: Fundación escuela para el desarrollo; Ediciones Desde Abajo; Universidad Nacional de Colombia, Facultad de Ciencias Económicas. Grupo de socioeconomía, instituciones y desarrollo.

Giraldo, G. C. A. (2007). ¿Protección o desprotección social? Bogotá: Desde abajo.

González, P. C. (1989). ¿El plebiscito para qué? Cien días vistos por Cinep, septiembre (7).

Jiménez, A. C. (2008). Democracia y neoliberalismo. Divergencias y convergencias en la construcción de la Carta Política de 1991. Medellín: La carreta Editores; IEPRI, Universidad Nacional de Colombia.

Kalmanovitz, S. (2001). Constitución y modelo económico. In J. A. Suárez (Ed.), El debate a la Constitución. Bogotá: Universidad Nacional de Colombia; ILSA; Unibiblos. 
Lamprea, M. E. (2011). La Constitución de 1991 y la crisis de la salud: encrucijadas y salidas. Bogotá: Universidad de los Andes.

Lemaitre, R. J. (2009). El derecho como conjuro. Bogotá: Siglo del Hombre Editores.

López, M. D. E. (2003). El constitucionalismo social: genealogía mundial y desarrollo local de los derechos sociales, económicos y culturales a partir de la Constitución colombiana de 1991. In B. C. M. Molina (Ed.), Corte Constitucional. 10 años balances y perspectivas. Bogotá D.C.: Universidad del Rosario.

López, M. D. E. (2008a). "Sistema de salud" y "derecho a la salud": Historia de su interrelación en la jurisprudencia constitucional. Bogotá: Informe preparado para ACEMI.

López, M. D. E. (2008b). Teoría impura del derecho: la transformación de la cultura jurídica latinoamericana (Legis Editores ed.). Bogotá: Legis; Ediciones Universidad de los Andes; Universidad Nacional de Colombia.

Medina, G. C., Toloza, F., Beltrán, A., Romero, P., \& Caicedo, M. (2009). FARC-EP. Temas y problemas nacionales 1958-2008. Bogotá: Universidad Nacional de Colombia, Facultad de Derecho y Ciencias Políticas y Sociales, Grupo de Investigación de Seguridad y Defensa Actores Armados.

Mejía, Q. O. (2002a). La Constitución de 1991 como proyecto inacabado. El otro derecho, Julio (28).

Mejía, Q. O. (2002b). La constitucionalización de la mentira. Dominación y exclusión en la Constitución del 91. Espaciocrítico.

Merryman, J. H. (1981). On the Convergence (and Divergence) of the Civil Law and the Common Law. Stanford Journal Of International Law, $17(2), 357-388$.

Moncayo, C. V. M. (1990). La crítica del discurso constitucional una urgencia política Asamblea Constitucional. ¿dilema jurídico o político? Bogotá: ILSA.

Moncayo, C. V. M. (2002). La Constitución de 1991 y el Estado de la nueva era del capitalismo El debate a la Constitución. Bogotá: Universidad Nacional de Colombia, ILSA.

Moncayo, C. V. M. (2004). El Leviatán Derrotado. Bogotá: Grupo Editorial Norma. 
Pérez, B. J. M. (2006). Coherencia y sistema jurídico. Madrid: Marcial Pons. Perry, G. (2011). Economía y Constitución. In F. d. C. S. Departamento de Ciencia Política, Universidad de los Andes (Ed.), Constitución de 1991, 20 años logros y pendientes. Bogotá: Universidad de los Andes; El Tiempo. .

Pisarello, G. (2010). El nuevo constitucionalimo latinoamericano y la constitución venezolana de 1999: balance de una década. Sin permiso, 6.

Rodríguez-Garavito, C. (2011). Beyond the Courtroom: The Impact of Judicial Activism on Socioeconomic Rights in Latin America. Texas Law Review, 89(1669), 1669-1698.

Rodríguez-Garavito, C. (2012). The Globalization of the Rule of Law: Neoliberalism, Neoconstitutionalism, and the Contest over Judicial Reform in Latin America Lawyers and the Transnationalization of the Rule of Law. New York: Routledge.

Semana. (1986, septiembre). LOS HOMBRES DEL PRESIDENTE. Recuperado el 20 de julio de 2019, de https://www.semana.com/especiales/articulo/los-hombres-del-presidente/8063-3

Stolowicz, B. (2012). A contracorriente de la hegemonía conservadora. Bogotá: Espacio Crítico-Centro de Estudios.

Uprimny, Y. R. (2001). Constitución de 1991, Estado Social y Derechos Humanos: promesas incumplidas, diagnóstico y perspectivas Paper presented at the Seminario de Evaluación Diez Años de la Constitución Colombiana 1991-2001, Bogotá.

Uprimny, Y. R. (2011). Las transformaciones constitucionales recientes en América Latina: tendencias y desafíos. In G. C. Rodríguez (Ed.), El derecho en América Latina. Un mal para el pensamiento jurídico del siglo XXI. Buenos Aires: Siglo Veintiuno Editores.

Valencia, V. H. (2010). Cartas de batalla: una crítica del constitucionalismo colombiano. Bogotá: Panamericana Editorial.

Zagrebelsky, G. (1999). El derecho dúctil. Madrid: Trotta. 